Information Sciences Letters

An International Journal

@ 2012 NSP

Natural Sciences Publishing Cor.

\title{
Analytical Evaluation of Tri-band Printed Antenna
}

\author{
Ilyas Saleem, Hamza Nawaz, Istaqlal Ahmed, S. Muzahir Abbas \\ Department of Electrical Engineering, COMSATS Institute of Information Technology, Islamabad, Pakistan \\ Email: ilyas-saleem@hotmail.com
}

\begin{abstract}
Simulated design and analysis of a simple tri-band microstrip antenna is presented in this paper A thin transmission line is used to excite the rectangular patch and FR4 epoxy with relative permittivity of 4.4 is used as substrate. To confirm the proficiency of proposed antenna, simulations have been performed in Ansoft HFSS (High Frequency Structure Simulator) a 3D electromagnetic field simulator, based on finite element method. Impedance bandwidths are determined on $-10 \mathrm{~dB}$ at resonating frequencies of 2.4, 3.3 and $5.3 \mathrm{GHz}$. An introduced design covers the requisite bandwidth for IEEE Wireless Local Area Network (WLAN) standards: $802.11 \mathrm{a} / \mathrm{n}, \mathrm{b} / \mathrm{g}$ (Wi-Fi), Bluetooth, ZigBee, and 802.16e (WiMAX). Multiband functionality, small size, light weightiness, plain configuration and conformability are the advantages; making the proposed design a good contender for integration in handheld wireless devices.
\end{abstract}

Keywords: Microstrip Patch, Transmission line, Tri-band, Relative Permittivity, Relative Permeability, Dielectric Loss Tangent.

\section{Introduction}

A rapid growth of wireless communications has been observed in recent years. IEEE launched several standards to satisfy the requirements of high data rate. IEEE 802.11a has higher data rate but with low range and IEEE $802.11 \mathrm{~b} / \mathrm{g}$ experiences interference from the other standards using the same frequency band. IEEE 802.11n and IEEE 802.16e support MIMO and WiMAX correspondingly. Now-a-days these technologies are functional with microstrip patch antennas $[1,2]$.

A compact and economical antenna which is integrate-able with RF and with Monolithic Microwave Integrated Circuits (MMICs) is preferred in mobile terminals [3]. Thus characteristics like flexibility, efficiency and simple fabrication made the patch antennas very attractive for wireless communications [4].

WLAN's are replacing short distance wired communication links $[5,6]$ although at designing stage compatibility is the main issue among various access points. Because of a user demands single portable device capable of working at different technologies for applications [7], which eventually becomes a reason to develop multi-standard end-user devices [8-10].

In this work, a tri band patch antenna operating at $2.4,3.3$, and $5.3 \mathrm{GHz}$ is presented. This paper is written in sections. Section II gives details about design; where comprehensive analysis and results are discussed in Section III, while Section IV concludes the paper.

\section{Antenna Design}

The geometry and dimensions of the simulated antenna are given in Fig. 1 and Table 1 respectively. 


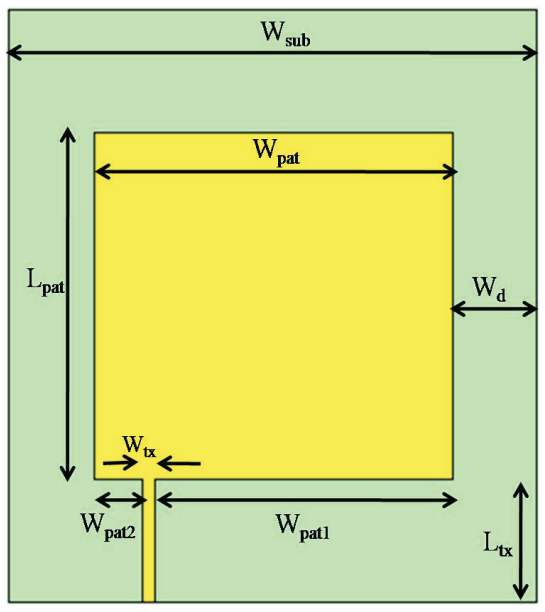

(a) Front View

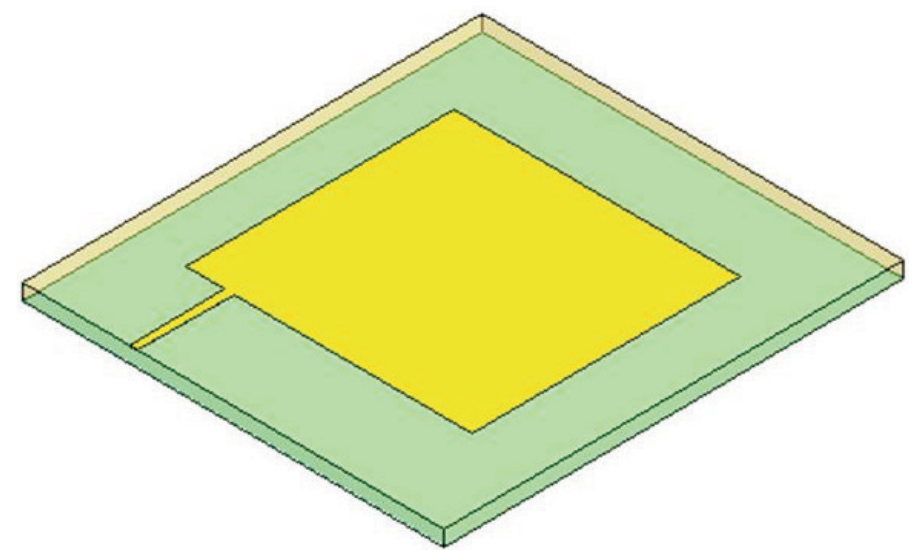

(b) Perspective View

Figure 1 Antenna Geometry

TABLE I. Antenna Dimensions

\begin{tabular}{|c|c|}
\hline Parameters & Length/Width (mm) \\
\hline $\mathrm{W}_{\text {sub }}$ & 44 \\
\hline $\mathrm{W}_{\text {pat }}$ & 30 \\
\hline $\mathrm{W}_{\text {pat } 1}$ & 24.87 \\
\hline $\mathrm{W}_{\text {pat } 2}$ & 4.13 \\
\hline $\mathrm{W}_{\mathrm{tx}}$ & 1 \\
\hline $\mathrm{W}_{\mathrm{d}}$ & 7 \\
\hline $\mathrm{L}_{\mathrm{pat}}$ & 28 \\
\hline $\mathrm{L}_{\mathrm{tx}}$ & 10 \\
\hline
\end{tabular}


Size of substrate is $48 \times 44 \mathrm{~mm}^{2}$ and complete ground plane is used. The patch is of $28 \times 30 \mathrm{~mm}^{2}$, where width $(W)$ and length $(L)$ of patch are determined by [3]. Feeding of proposed antenna is done by transmission line, whose length $\left(L_{t x}\right)$ is $10 \mathrm{~mm}$ and width $\left(W_{t x}\right)$ is calculated from (1) [3].

$$
Z_{c}=\frac{60}{\sqrt{\varepsilon_{r e f f}}} \ln \left[\frac{8 h}{W_{t x}}+\frac{W_{t x}}{4 h}\right]
$$

Equation (1) validates, only if:

$$
\frac{W_{t x}}{h} \leq 1
$$

In (2): $\left(W_{t x}\right)$ is width of transmission line where $\mathrm{h}$ is $1.6 \mathrm{~mm}$, height of substrate. To solve ; $\left(W_{t x}\right)$, the impedance of transmission line taken $75 \Omega$ in (1). To get effective relative permittivity $\left(\varepsilon_{\text {reff }}\right)$, numerical values of relative permittivity $(\varepsilon)$ and $(W)$ were inserted in (14-1) of [3]. In addition, width $W_{g}$ and length $L_{g}$ of ground plane are computed using (3) and (4).

$$
\begin{aligned}
& L_{g} \approx 12 h+L \\
& W_{g} \approx 8 h+W
\end{aligned}
$$

\section{3..Analysis and Results}

Comparisons carried out in HFSS are discussed below. In our case: $\left(W_{t x}\right)$ is $1 \mathrm{~mm}$ that is optimum; however Fig. 2 shows the variation of return loss with different $\left(W_{t x}\right)$. The trend was that at small $\left(W_{t x}\right)$, return loss of higher frequencies decreased and vice versa.

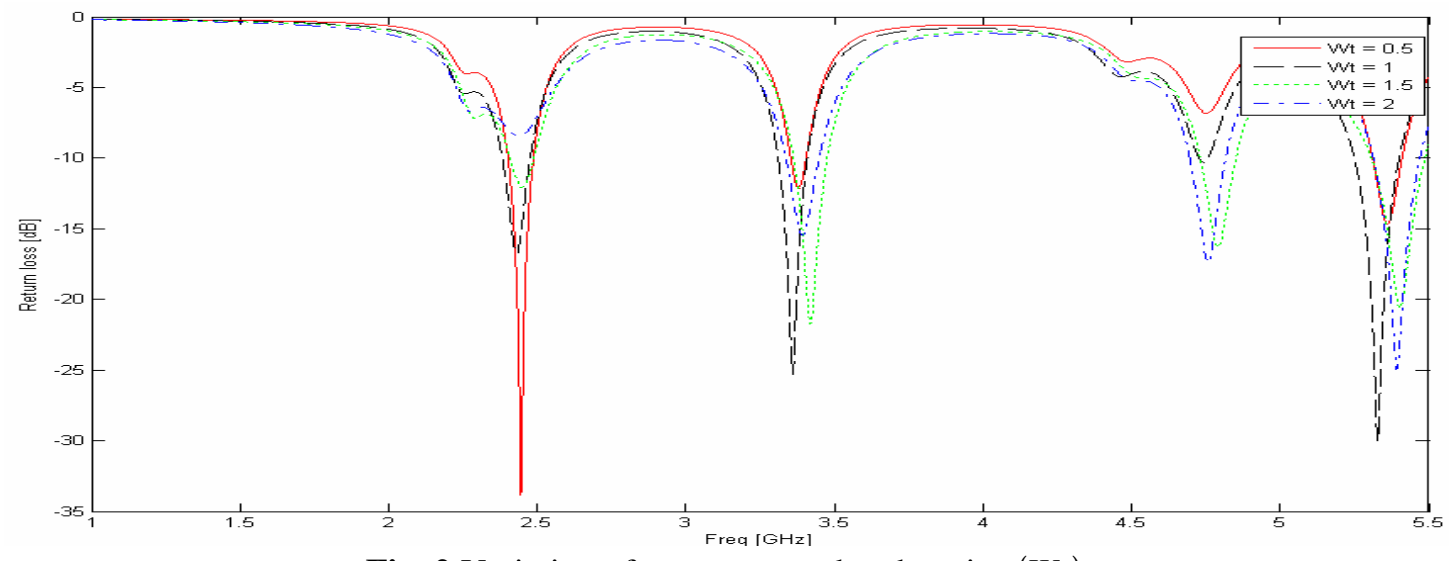

Fig. 2 Variation of s-parameters by changing $\left(W_{t x}\right)$

Then, copper sheet of patch and ground plane was replaced one at a time with aluminum, bronze and golden keeping an antenna dimensions same. The effect on s-parameters is shown in Fig. 3. It can be seen clearly that the bandwidth increases negligibly. 


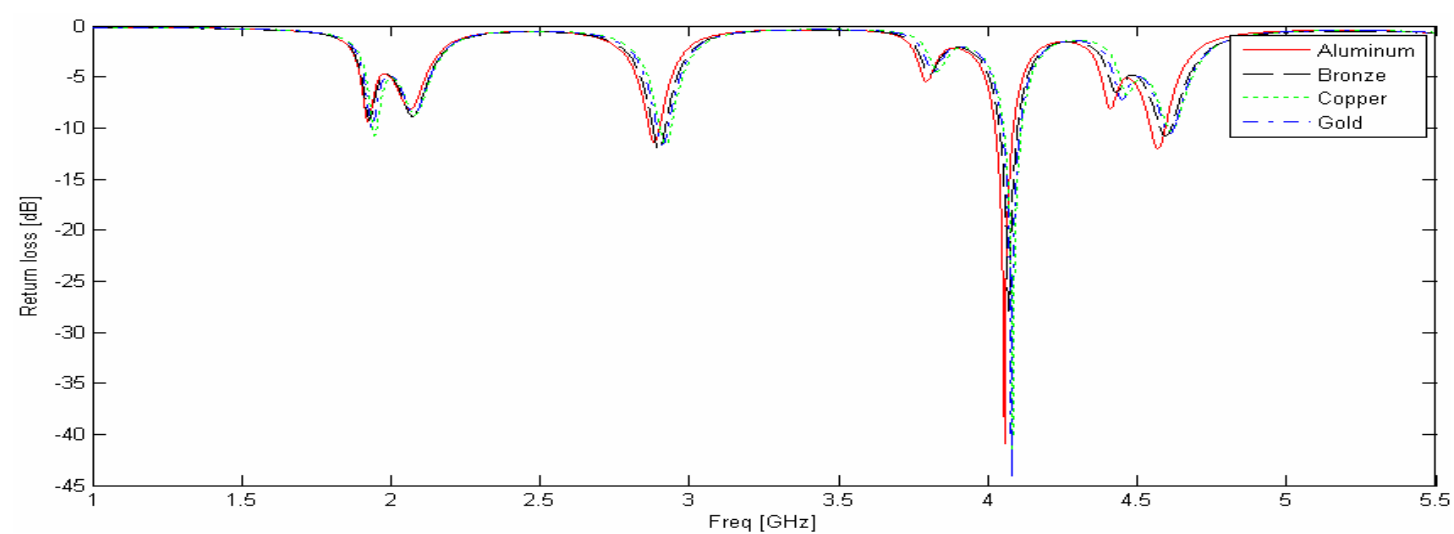

Fig. 3 Bandwidth comparison for different conducting sheets

Also substrates with different relative permittivities $(\varepsilon)$ were used. FR4 epoxy was used at the start and consequent substrates were chosen by (5).

$$
\varepsilon \approx k \pm 1.9
$$

In (5), value of $\kappa$ is 4.4 that is relative permittivity of FR4. In Table 2, important parameters of the materials used in simulation are given where relative permeability is constant. Changing $(\varepsilon)$ changes the basic design and size of microstrip antenna. Indeed, our concern was to keep the original geometry unchanged and study the results by $(\varepsilon)$.

TABLE II. Significant Parameters of Different Materials

\begin{tabular}{|c|c|c|c|}
\hline Material Used & Relative Permittivity & Relative Permeability & Dielectric Loss Tangent \\
\hline Arlon DiClad 880 & 2.2 & 1 & 0.001 \\
\hline FR4 Epoxy & 4.4 & 1 & 0.02 \\
\hline Rogers RT/duroid 6006 & 6.15 & 1 & 0.0019 \\
\hline Taconic RF-60 & 6.15 & 1 & 0.0028 \\
\hline
\end{tabular}

It is shown in Fig. 4 that substrates with higher $(\varepsilon)$ offers an operational band at $4 \mathrm{GHz}$ with small bandwidth where substrates having less $(\varepsilon)$ provides multiband with better efficiency.

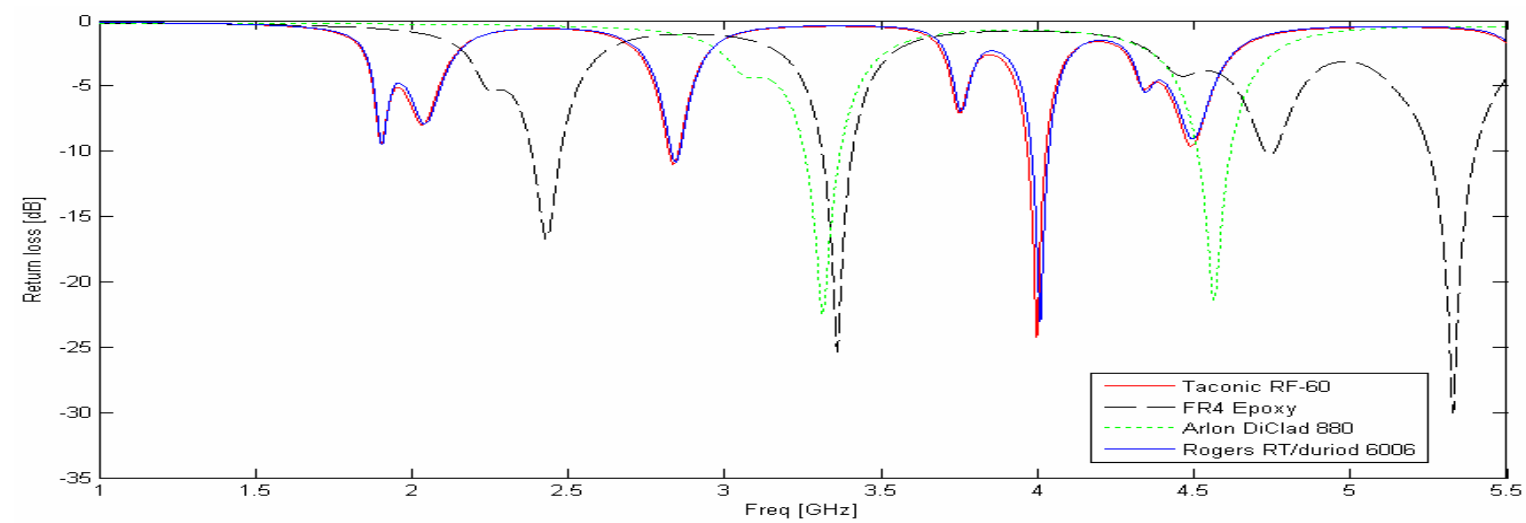

Fig. 4 Frequency shift for different substrates keeping antenna dimensions same 
Moreover, the transmission line is placed on left side to excite current on non-radiating edges causing surface current to travel in two orthogonal directions and to generate fine radiations favorable for multifrequency operation. Simulated gain is $1.5 \mathrm{dBi}$ nearly constant over the whole frequency.

\section{Conclusion}

A patch antenna is simulated in HFSS, operating at 2.4,3.3, and $5.3 \mathrm{GHz}$. A comparative analysis has been done and the competency of presented design is verified by using various conducting sheets and substrate causing it applicable for Wi-Fi, Bluetooth, ZigBee, and WiMAX.

\section{References}

[1] D. M. Pozar, Microstrip Antennas, IEEE Transaction on Antenna and Propagation, $79-91$ (1992).

[2] Bhal and Bhartia, Microstrip Antenna Design- Handbook, Artech House, London (2001).

[3] Constantine A. Balanis, Antenna Theory: Analysis and Design, Wiley, New York, (1997).

[4] K. L. Wong, A Printed Triple-Band Antenna for WiFi and WiMAX Applications, Wiley, New York (1999).

[5] F. Thudor, A. Louzir, An Extremely Compact Pattern Diversity Antenna for WLAN, IEEE AP-S Int. Symp. Dig., 60-63 (2002).

[6] S.-H. Yaeh, K. L. Wong, Dual-Band F-Shaped Monopole Antenna for 2.4/5.2 GHz WLAN Applications, IEEE AP-S Int. Symp. Dig., $72-75$ (2002).

[7] D. Liu, B. Gaucher, E. Flint, Integrated Laptop Antennas - Design and Evaluation, IEEE AP-S International Symposium and USNC/URSI National Radio Science Meeting, (2001).

[8] I-Fong Chen, Chia-Mei Peng, Microstrip-Fed Dual-U-Shaped Printed Monopole Antenna for Dual Band Wireless Communication Applications, Electronics Letters, 955-956 (2003).

[9] Jen-Yea Jan, Liang-Chih Tseng, Small Planar Monopole Antenna with a Shorted Parasitic Inverted-L Wire for Wireless Communications in the 2.4, 5.2, and 5.8 GHz Bands, IEEE Transaction on Antennas and Propagation, 1903-1905 (2004).

[10]Ya-Ying Wang, Shyh-Jong Chung, A New Dual- Band Antenna for WLAN Applications, IEEE AP-S Int. Symp., 20-25 (2004). 